Document downloaded from:

http://hdl.handle.net/10251/63037

This paper must be cited as:

Vargas, A.; Boza Garcia, A.; Patel, S.; Patel, D.; Cuenca González, ML.; Ortiz Bas, A. (2015). Inter-enterprise architecture as a tool to empower decision-making in hierarchical collaborative production planning. Data and Knowledge Engineering. 1-18. doi:10.1016/j.datak.2015.10.002.

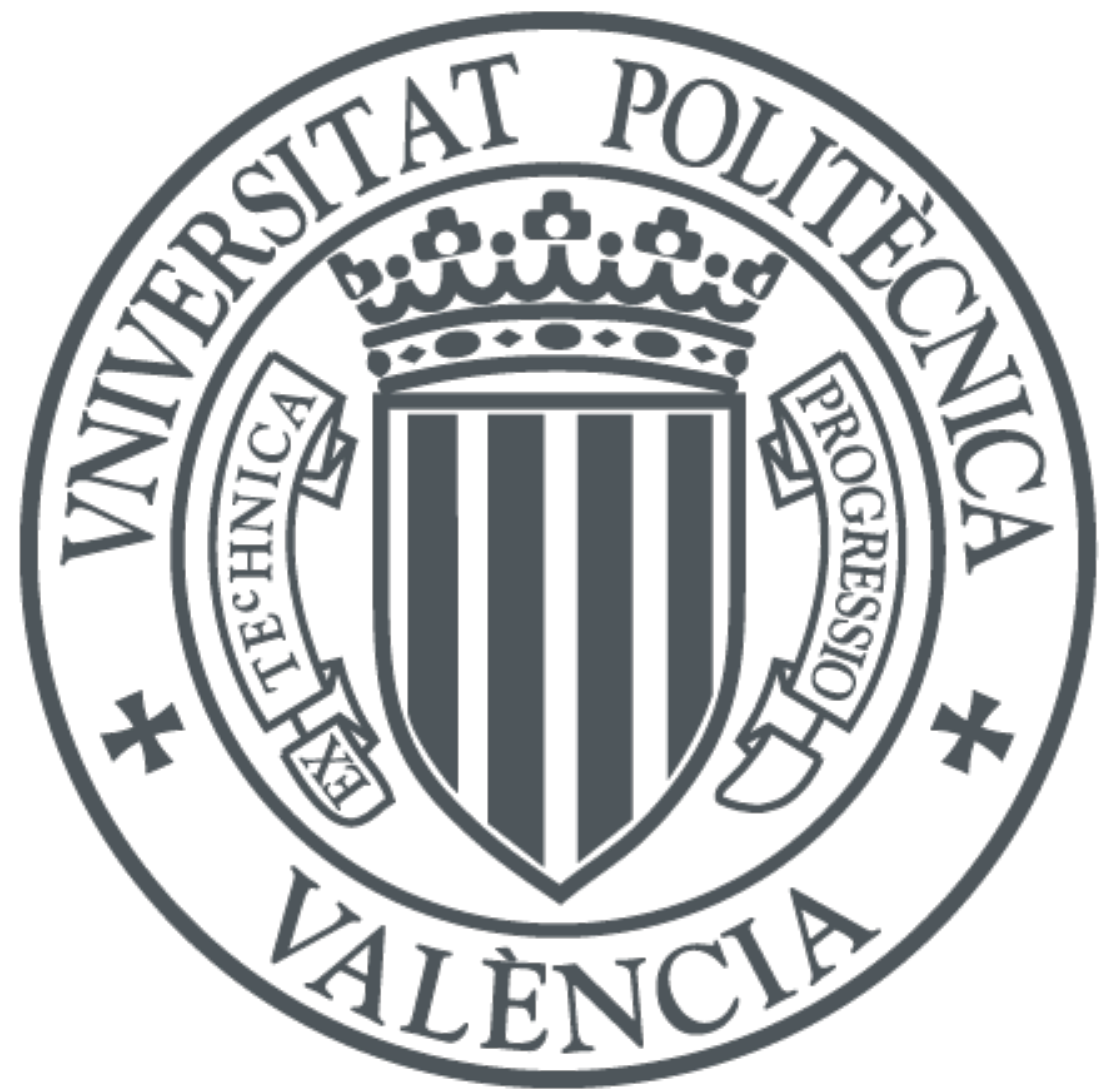

The final publication is available at

http://dx.doi.org/10.1016/j.datak.2015.10.002

Copyright Elsevier

Additional Information 


\title{
INTER-ENTERPRISE ARCHITECTURE AS A TOOL TO EMPOWER DECISION MAKING IN HIERARCHICAL COLLABORATIVE PRODUCTION PLANNING
}

\author{
Alix Vargas ${ }^{1}$, Andres Boza $^{1}$, Shushma Patel ${ }^{2}$, Dilip Patel $^{2}$, Llanos Cuenca ${ }^{1}$, Angel Ortiz ${ }^{1}$ \\ ${ }^{1}$ Centro de Investigación en Gestión e Ingeniería de Producción (CIGIP). Universitat Politècnica de València. \\ Camino de Vera s/n Ed 8G - ${ }^{\circ}$ y $4^{\circ}$ planta Acc D (Ciudad Politécnica de la Innovación) Valencia Spain. \\ alvarlo@posgrado.upv.es, aboza@cigip.upv.es, llcuenca@cigip.upv.es, aortiz@cigip.upv.es \\ ${ }^{2}$ London South Bank University, School of Engineering, 103 Borough Road, SE1 0AA, London, United \\ Kingdom \\ shushma@1sbu.ac.uk,dilip@1sbu.ac.uk
}

\begin{abstract}
The novel idea of inter-enterprise architecture from the enterprise engineering perspective allows collaborative networks to integrate and coordinate different organizations. Therefore, interenterprise architecture offers multiple benefits, including: joint process harmonization, business strategy and information technology alignment, technological cost reduction, risk and redundancies reduction, customer services improvement and enhanced responsiveness. Inter-enterprise architecture can be used to solve the different issues that collaborative networks face on a daily basis. A conceptual model that addresses the problem of unexpected events management in the context of hierarchical production planning to improve decision making in collaborative environments is proposed using of inter-enterprise architecture. The proposed conceptual model comprises of a framework, a modelling language and the methodology. The conceptual model has been applied to a Spanish collaborative network from the ceramic tile sector.
\end{abstract}

Keywords: inter-enterprise architecture, decision-making, hierarchical production planning, collaborative networks, unexpected events

\section{Introduction}

The rapidly changing economic and global environment necessitates companies to evolve in order to react effectively to continuous and varying changes. As a result, companies need to engage in collaborative networks $(\mathrm{CN})$ to effectively and synergistically overcome these vicissitudes. To enable this, inter-enterprise architecture (IEA) facilitates the integration of business processes with collaborative networks, in line with existing Information Systems/ Information Technology (IS/IT) [1].

Information technology improves the value chain by changing the way companies do business [2]. Decision support systems (DSS) as part of IS/IT, support decision-making processes in different situations, such as: production planning, inventory control, purchase planning, and distribution planning among others. In this paper, we focus on the use of decision support systems in the context of hierarchical production planning (HPP) in collaborative environments. 
Production planning is extremely complex, and therefore it is difficult to develop a single model to represent the complexity. Hierarchical production planning facilitates decision-making by decomposing the problem into sub-problems, in the context of an organizational hierarchy where decisions of the higher levels impose restrictions at the lower levels [3], which supports the development of manageable models and views. Decision support systems for hierarchical production planning rapidly guide decision makers to assimilate information and ensure effective decision-making. However, most systems are designed without taking into account different unexpected events or disruptions, because of the perceived difficulty of representing uncertainty in the models.

There is little empirical evidence connecting the fields of inter-enterprise architecture, hierarchical production planning and decision support systems, which leads to the question: "Is it possible to link the above fields to solve the problem of unexpected events in hierarchical production planning?". In order to answer this question, this paper presents a review of the fields and their relationships, and sets out the research question. The main components of the inter-enterprise architecture that address the specific problem of unexpected events in hierarchical production planning are proposed. The conceptual model is applied to and validated on a collaborative network scenario based the Spanish ceramic tile sector.

The paper is structured as follows: Section 2 describes the related work in the fields of: enterprise architecture, hierarchical production planning and decision support systems. Section 3 presents the conceptual model of the inter-enterprise architecture, which integrates the three main components (framework, modelling language and methodology) that address the challenges and problems of unexpected events handling in hierarchical production planning to enable collaboration between organisations that make up the supply chain. Section 4 presents the application of the proposed conceptual model of inter-enterprise architecture to the case study. In section 5 the results, main conclusions and suggestions for further work are presented.

\section{Related work}

\subsection{Inter-enterprise architecture}

The area of enterprise architecture stems from the field of enterprise engineering. Enterprise architecture provides a set of principles, methods, models and tools for analysing, designing and redesigning elements, such as, organizational structures, human resources, business processes, information systems and technology infrastructure and identifying the relationships and linkages between these elements. Therefore enterprise architectures enable the company to be represented in a holistic and integrated perspective, to achieve the business objectives and facilitate decision-making [4]. In recent years, a number of enterprise architectures have been proposed, including: CIMOSA [5], GIM-GRAI [6], PERA [7]; GERAM [8], IE-GIP [9,10,11,12,13] ARIS [14] and TOGAF-ADM [15]. 
The common high level elements that link these enterprise architectures together are: framework, methodology, and modelling language [16]. These elements must be included in enterprise architectures for successful implementation within the organisation, allowing to model enterprises holistically. The framework represents a simple structure of the elements that make up the enterprise [12] and shows how the elements are related and integrated. The modelling language allows for modelling, organizing and understanding the relationships between elements of the enterprise using building blocks to describe them [4]. The methodology facilitates the implementation of the framework, step-by-step through the use of the building blocks defined by the modelling language [17].

Vargas et al. [1], proposed the concept of inter-enterprise architecture (IEA) by investigating the application of enterprise architecture in collaborative enterprises. As a result of the study, enterprise architecture was adapted and extended to support the modelling of collaborative environments by integrating several enterprises that make up the supply chains and networks. Inter-enterprise architecture supports the integration of collaborative processes in enterprises with their information systems and technology systems, to support joint processes, reducing risks and redundancies and increasing customer service responsiveness. Inter-enterprise architecture can be applied to different decision domains in collaborative networks, such as strategic planning, procurement planning, inventory planning, production and control planning, and distribution and logistics planning. In this paper, we focus only on production planning and specifically hierarchical production planning in order to facilitate decision-making in collaborative networks. The following sections describe the main elements of hierarchical production planning and decision support systems and their relationship.

\subsection{Hierarchical production planning (HPP)}

To reduce the complexity of the system, collaborative and productive activities, and in particular planning and control, should follow a hierarchical approach that allows coordination between the objectives, plans and activities at strategic, tactical and operational levels [18]. In this hierarchical approach, each level will pursue its own goals, but will be constrained by the higher level, on which they depend, and will result in restricting the lower level $[\mathbf{1 9}, 20]$. In the hierarchical production planning systems, the decisions problems are split into sub-problems. Each sub-problem corresponds to a decision-making level in the organizational structure, and mathematical decision models are constructed to solve each sub-problem, which have different planning horizons, and allows the aggregation and disaggregation of information across hierarchical levels [21].

The classical tools available for production planning are not designed to handle uncertainty or respond to unexpected events. When an unexpected event occurs during production, production managers try to fix them manually which is often inefficient, or through costly re-planning of production planning schedules $[22,23]$. These approaches often lead to long production stoppages, reducing productivity and continuity of the chain, and decreasing customer service. Therefore, the lack of proper management of 
unexpected events in production planning creates a bottleneck that must be addressed in a timely and efficient manner [24]. Disregarding the management of unexpected events in production planning means response times and current inventories are often excessive, while resource utilization is low and end dates of the products cannot be controlled with precision [25]. Current planning techniques focus on optimizing the manufacturing flow with deterministic data storages locally. All this results in the need to design and create new tools to optimize the overall production flow along the collaborative networks, taking into account the different types of unexpected events that may occur.

In the context of production planning the arrival of unexpected events affect the normal planning performance. Preparation for unexpected events, such as the lack of available material, rush orders, production time variation, quality problems and faulty machines, is vital to guaranteeing business continuity. Therefore, these events need to be addressed by the hierarchical production planning systems. How to handle unexpected events through flexible and robust manufacturing systems have previously been discussed in the literature $[26,27]$. However, most of the work in these areas only considers certain types of unexpected events such as lack of available materials, production time variations and rush orders, or provide limited assistance to the way people react. There are no practical cases or research that takes into account the management of different types of unexpected events in an integral way.

The ideal iteration of a production planning system is to be able to detect abnormal behaviour in the system, determining the type of disruption and continuously proposing alternatives depending on the type of event that occurred. Determining the type of unexpected event is important because the system will be affected differently by each type of event, and requires different decisions to be made. Production systems that are able to react to various unexpected events, have to achieve the goal of a coordinated adaptive behaviour during execution of production activities, by responding dynamically to changes that occur while customer demand is satisfied in a cost-effective way [28]. In this type of system, it is important that the system acquires historical data and information to learn from past events [29].

Darmoul et al [26], define a typology of the different kinds of unexpected events or failures that can happen in a manufacturing system and therefore affect production planning. This typology defines that unexpected events could originate from the following entities: suppliers, resources, products and customers. Each of these entities would generate specific unexpected events that are related to them. A number of authors: $[18,21,23,27,30,31,32,33,34,35,36,37,38,39]$ have identified a number of unexpected events and partially or completely agree with Darmoul et al [26]. In the literature, an additional specific unexpected event, production time variation, has also been proposed [ $21,23,25,31,37,38]$. This event can be added to the "production" typology. Table 1 shows an extension of these specific events based on empirical evidence collected from our case study. In Table 1 grey cells represent the extension of this typology and the table maps the relationships between the theoretical and empirical definitions. 
Table 1. Unexpected events definition from theoretical and empirical points of view

\begin{tabular}{|c|c|c|}
\hline Entity & $\begin{array}{c}\text { Theoretical unexpected event } \\
\text { definition }\end{array}$ & $\begin{array}{c}\text { Empirical unexpected event } \\
\text { definition }\end{array}$ \\
\hline \multirow{3}{*}{ Supply } & Delays & Delays \\
\hline & \multirow{2}{*}{ Quality problems } & Difference in quantity ordered \\
\hline & & Quality problems \\
\hline \multirow{6}{*}{ Resource } & Machine breakdowns & Machine breakdowns \\
\hline & Tools breakage & Tools breakage \\
\hline & \multirow{4}{*}{ Labour problems } & Workers sickness \\
\hline & & Workers under performance \\
\hline & & Workers high performance \\
\hline & & Strike \\
\hline \multirow{8}{*}{ Production } & \multirow{2}{*}{ Scraps management } & Low raw material utilization \\
\hline & & High raw material utilization \\
\hline & Quality problems & Quality problems \\
\hline & \multirow{2}{*}{ Production times variation } & Low performance in production \\
\hline & & High performance in production \\
\hline & \multirow{3}{*}{ Product rejection } & Returns for low quality \\
\hline & & Returns for delay in delivery \\
\hline & & Refunds for early delivery \\
\hline \multirow{3}{*}{ Customer } & Rush orders & Rush orders \\
\hline & Order modification & Order modification \\
\hline & Order cancelation & Order cancelation \\
\hline
\end{tabular}

In order to manage each and every specific unexpected event in an integral way, it is necessary to consider different factors for its management such as, duration of the disturbance (estimation of how long can an unexpected event last) and criticality of the resources involved (which relates to substitution of resources) [30], as well as the impact (high: related to strategic decisions, or low: related to operational or tactical decisions) [27].

\subsection{Decision Support Systems (DSS)}

Information systems, which provide necessary information for managers to make their decision, have become key elements in the decision-making process. Therefore, decision support systems are indispensable tools not only to obtain an optimal solution, but also how to obtain a broad and deep view of the problem.

A decision support system can be defined as: "an interactive information system used by decision-makers, which is flexible and adaptable based on information technology, models and data with the purpose of supporting decision-making, providing useful information to decision-makers at all levels of an organization, enabling the achievement of the objectives set by the organization" $[40,41,42,43]$.

According to [43] and [42] the three main components of decision support systems are: Database Management Systems (DBMS), Model Base Management Systems (MBMS) and the User Interface Systems (UIS). The implementation of these components depends on each decision context. In the next section, the role of decision support systems in relation to hierarchical production planning is considered. 


\subsubsection{Decision support systems and hierarchical production planning}

Information systems within organizations are becoming more important to support intercompany transactions, as well as to facilitate decision-making through increasingly complex systems that guide decision makers in processes where it is necessary to assimilate large volumes of information in a short period of time to ensure effective decision-making.

A hierarchical production planning system must be able to detect abnormal behaviour, determine the type of disruption and continually propose alternatives depending on the type of event. Determining the type of unexpected event is important because the process will be affected differently and will require different decisions to make. In this context, the way the decision maker sees the information can accelerate his/her perception, provide insight and control, and harness the large volume of valuable data to gain a competitive advantage in making decisions [44].

Collaborative networks will need to adjust processes, products and services in a competitive market, adapting to new organizational forms, and providing flexibility [45]. Therefore, more agile processes for assertive decision-making are necessary for collaborative networks. Hierarchical production planning systems need to be sufficiently flexible in order to adapt to the dynamic environments. The area of flexibility within the context of hierarchical production planning systems has been studied and different solution proposed $[46,47,48,49,19]$. Their work demonstrates how the data model can be integrated with the hierarchical planning system. In addition to this Boza et al. [20] state that the logical building blocks that play an interactive role in the information system and decision technologies for hierarchical production planning are:

- Data Modelling (DaM): Represents the internal structure and the external presentation of the data.

- Decision Modelling (DeM): Defines the models that represent the addressed problem. These models are used to evaluate possible decisions in a problem domain.

- Model analysis and research (MAR): This is the instantiation of decision model with data, model evaluation and results.

So far, there is little evidence of research using decision support systems for hierarchical production planning that includes unexpected events that allow business continuity, a gap in the research we address in this paper. It is possible to use interenterprise architecture for modelling the trends for adopting decision support systems in hierarchical production planning to address the specific problem of handling unexpected events.

\section{Proposed IEA Conceptual Model}

Before discussing the main components of the inter-enterprise architecture, it is important to illustrate, through a scenario (Figure 1). In the hierarchical production planning 
scenario, the interaction between the companies is shown, without considering unexpected events.

As shown in Figure 1, company 1 (leader) generates the production plan at the strategic level, where the data is aggregated by product families with a horizon planning of one year and a review period of three months based on their forecasted demand. At the tactical level, the aggregate planning is communicated into the same company and the production plan is generated, based on the planning and confirmed sales, stock levels, capacity and costs. The horizon planning at this level is 3 months with a review period of 1 month. Based on this plan, the Material Requirements Planning (MRP) is generated and disaggregated in products. This MRP generates product purchase orders that are communicated to the suppliers. Each supplier, based on the information received from the lead company and the internal information on stock levels, capacity and costs, generates its own production plan and MRP aggregated in products. This is disaggregated in components to generate component purchase orders, which are communicated to second tier suppliers. Depending on this information each of these companies communicates to the lead company, whether or not it is possible to meet the order requirements on time. If the company cannot fulfil the order on time, the information on how many units that can be supplied and the delivery times is communicated to the lead company, thus enabling them to review their tactical plan.

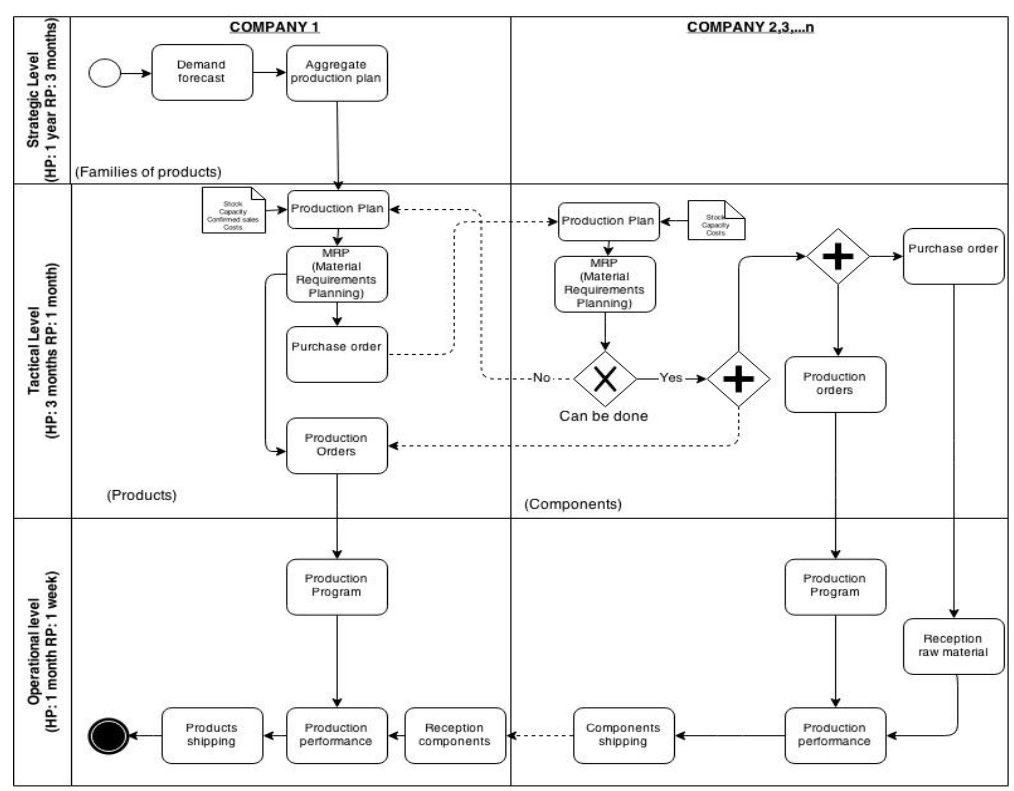

Figure 1. Collaboration workflow for hierarchical production planning

If all the companies can deliver the orders within the agreed timeframe, the production orders are generated for both the leader and suppliers. The suppliers also have to generate purchase orders of raw materials needed to manufacture the necessary components for the production of end products for the leader. Finally at the operational level, horizon planning is one month and it is reviewed weekly. The raw materials are 
received by the supplier and the components are manufactured and delivered to the leader. The lead company assembles or manufactures the final product, which is then delivered to the end customer. It is clear this case scenario is already complex and it is further complicated by including unexpected events in the model, that further impede the normal business continuity. Therefore it is important to have decision tools to allow collaborative networks to manage unexpected events in hierarchical production planning.

The proposed conceptual model provides tools to companies that have collaborative networks to help them improve the unexpected events management process in the context of hierarchical production planning, based on inter-enterprise architecture. The approach can provide the basis for the creation of flexible decision support systems, so that decision makers have alternative courses of action to maintain continuity, depending on the type and magnitude of the unexpected event.

As stated in Section 2.1, an inter-enterprise architecture is considered complete when it includes the following elements, as a minimum: framework, methodology and modelling language. Therefore the present architecture is structured according to this premise, based on IE-GIP (the Spanish acronym that translates to 'Enterprise Integration - Business Processes and Integrated Management'), one architecture used in academy and industry in Spain, which has its foundations in CIMOSA and PERA. The reasons behind the selection of this architecture and its comparison with others important architectures are shown in [50]

\subsection{Framework}

In proposing a useful framework for modelling an inter-enterprise architecture, to facilitate unexpected events management on hierarchical production planning, IE-GIP is the basis of the general framework used to propose a partial framework to solve this problem. Thus, the phases of the life cycle and modelling views of IE-GIP are taken into account in the design of the partial model. Figure 2 graphically presents the situation of the partial framework that we are proposing (shadow in black colour), based on the general framework IE-GIP.

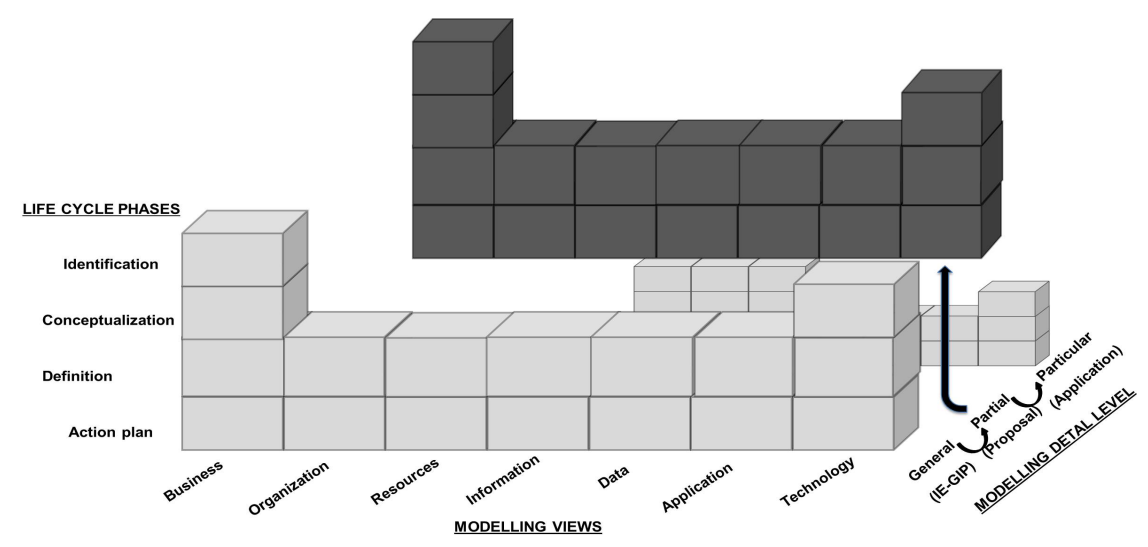

Figure 2. Situation partial framework related to IE-GIP. 
The proposed partial framework maintains the life cycle phases of IE-GIP at its macro level, because all the strategic and tactical elements are defined at this level and these elements represent the basis for the conceptualization, design and plan of action. The phases of the life cycle are interrelated, so the elements of each phase restrict and depend with one another, thus integration in the model is warranted. On the other hand, the modelling views have been merged, added or evolved, looking for a partial definition that address the problem of unexpected events' handling that IE-GIP's modelling views have not covered. The life cycle phases and modelling views proposed for this partial framework are described as follow:

Life Cycle Phases: The life cycle phases are a state of development in the life cycle of a collaborative network. Below is a brief description of each phase for the collaborative network scope:

- Identification: The identification phase covers the identification of the domain to be modelled in terms of strategic business objectives and the relationship of the domain with the elements of their environment. The domain is the hierarchical production planning and unexpected events management. In this phase, it is necessary to collect the information and data about stakeholders, members of each company involved in the collaboration (organizational units), teams (organizational cells) and their relation with one another.

- Conceptualization: The conceptualization phase defines business concepts that enable the achievement of business objectives and mastering operations including all the strategic elements necessary to achieve the basic functionality of the domain. It is jointly defined by business strategy and IS / IT strategy, which must be aligned with one another. At the same time, in general terms determine how and what information is going to be shared and how units and cells (specified in detail later) are involved in the joint process.

- Definition: The definition phase describes the functions of business in a specific domain in terms of business processes, business activities and inputs and outputs. It defines the objectives to be met to solve the problem of managing unexpected events resulting in meeting the associated key performance indicators (KPIs). It is also necessary to define the way each stakeholder is performing its AS-IS processes and how they want to reach a TO-BE state in the global domain (CN Processes). As a final point in this phase, the definition of the unexpected events and the decisional, data and analysis models associated to this, have to be completed.

- Action plan: The action plan describes the information necessary to perform all tasks relating to the collaboration process and how it is going to be communicated to the members of the organizations involved in the collaborative domain.

Modelling views: The definition of the modelling view takes into account two approaches: the architecture IE-GIP $[\mathbf{9 , 1 1}]$ and the Framework for a Decision Support Systems in a Hierarchical Extended Enterprise (FDSSHEE) proposed by Boza et al [20]. Figure 3 shows a comparative analysis of the origin of the views of our framework. Seven modelling views have been proposed, in order to achieve a complete and integral model for collaborative networks in the context of hierarchical production planning for 
unexpected events. The classical function view has been split into two different views: business and process, in order to facilitate the modelling, because the business view is focused on strategic issues, and the process view is focused on tactical and operational aspects. The organizational and resources views maintain the same structure as proposed in IE-GIP. The decision view has been added taking into account the elements proposed in FDSSHEE, in order to model the decision making process needed for solving the problem of unexpected events management. The data view and information view of IEGIP and the element related to data management in FDSSHEE have been joined together into the data view, so that the elements can be modeled together to simplify the complexity of the modeling. Finally, the application and technology views of IE-GIP and the element related with analysis and applications of FDSSHEE have been merged into the IS/IT view in order to collect and model all the information and elements related to information technology.

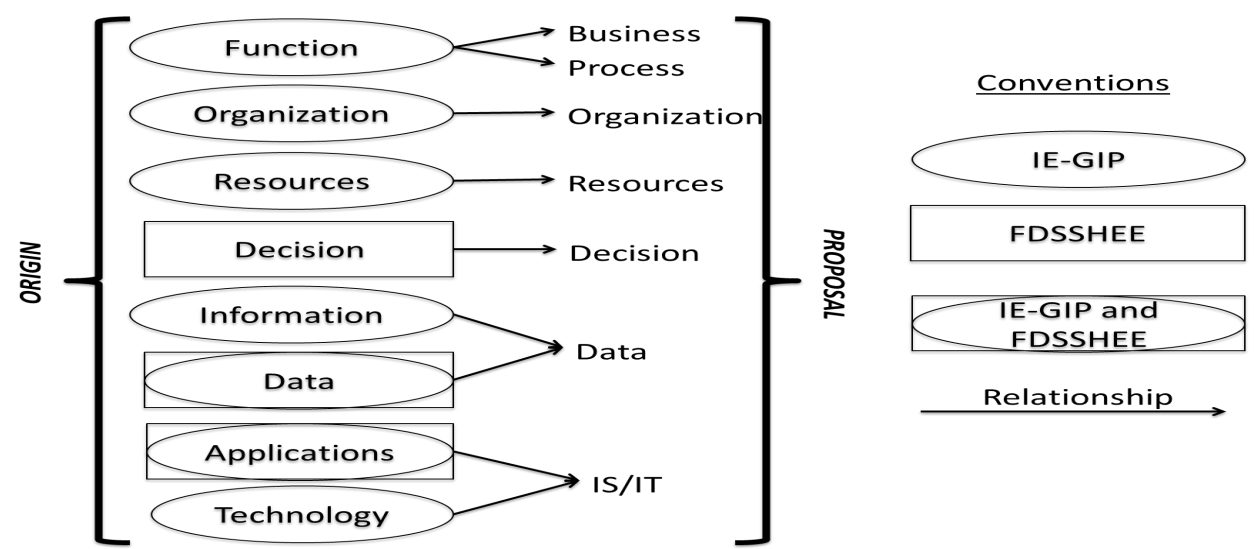

Figure 3. Mapping of the original modelling views to the proposed modelling view below

The proposed modelling view descriptions, identified in Figure 3, above are defined

- Business view: This view represents the strategic aspects that must be taken into account in the collaborative network, including stakeholders, domain, business strategy, objectives and performance assessment [11].

- Process view: This view includes a definition of the AS-IS processes and TO-BE processes, operation and processes improvement and how unexpected events should be managed $[51,52,53]$.

- Organization view: This view allows the representation and modification of organizational and hierarchical structures of the collaborative network and the cells and units involved in the domain $[\boldsymbol{8}]$.

- Resources view: This view represents the needed resources to complete business processes in the specific domain. This view includes physical and human resources $[8]$. 
- Decision view: This view refers to the decision-making system that has to be adopted for the business process managers. This view is invaluable to determine how the decisions are made in the planning process [6].

- Data view: Data is a valuable resource for organizations that provides information, thus data view and information view have been merged in a unique view, ensuring integration in the modelling. In the continuous learning process organizations are involved in, the information that they handle becomes knowledge. Thus, it is a differentiating asset of collaborative networks [54].

- Information Systems / Information Technology (IS/IT) view: This view defines what kind of applications and technology are relevant to the collaborative network, the IS/IT strategy that must follow the collaborative network that is aligned with the business strategy [12] and finally the analysis model that seeks to link the decision modelling and data modelling.

Figure 4 graphically represents our proposal of a partial framework for unexpected events management on hierarchical production planning. Each cell in the partial framework for managing unexpected events represents the intersection of a particular life cycle phase with one modelling view. Not all views include all life cycle phases. For instance, the views of process, data and IS/IT do not require the definition of elements in the beginning of the life cycle due to the fact that their core is in the definition and action plan.

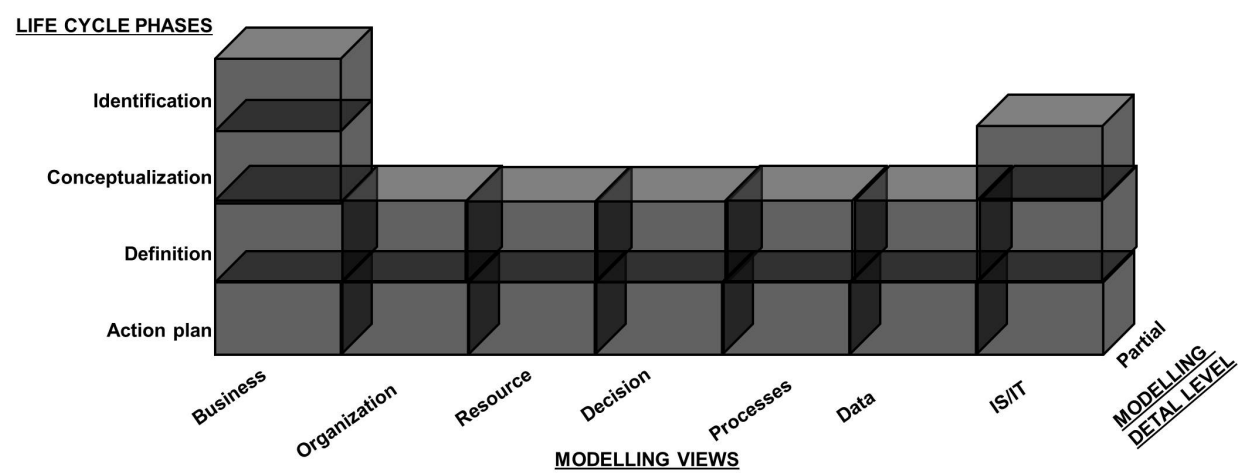

Figure 4. Partial framework for managing unexpected events on HPP

\subsection{Modelling language}

The modelling language in the proposed conceptual model is based on a common generic set of building blocks that simplify the creation of business models, increasing efficiency in modelling and allowing greater understanding and interoperability between companies that implement it [55]. It is important to define the building blocks in order to model collaborative networks, which supports all phases of the life cycle. However, this does not mean that different building blocks exist for each phase of the life cycle. The same building blocks can be reused in subsequent phases, providing new and better attributes 
for capturing information that facilitates modelling. Figure 5 shows the building blocks of the proposed conceptual model in relation to IE-GIP. Each building block is briefly described below:

1. Domain (DO) represents the boundaries of the collaborative network in the collaborative context of hierarchical production planning to solve the problem of unexpected events handling.

2. Stakeholder (SH) represents the number or nodes in the collaborative network that participate in the collaborative domain. The minimum number of nodes must be two.

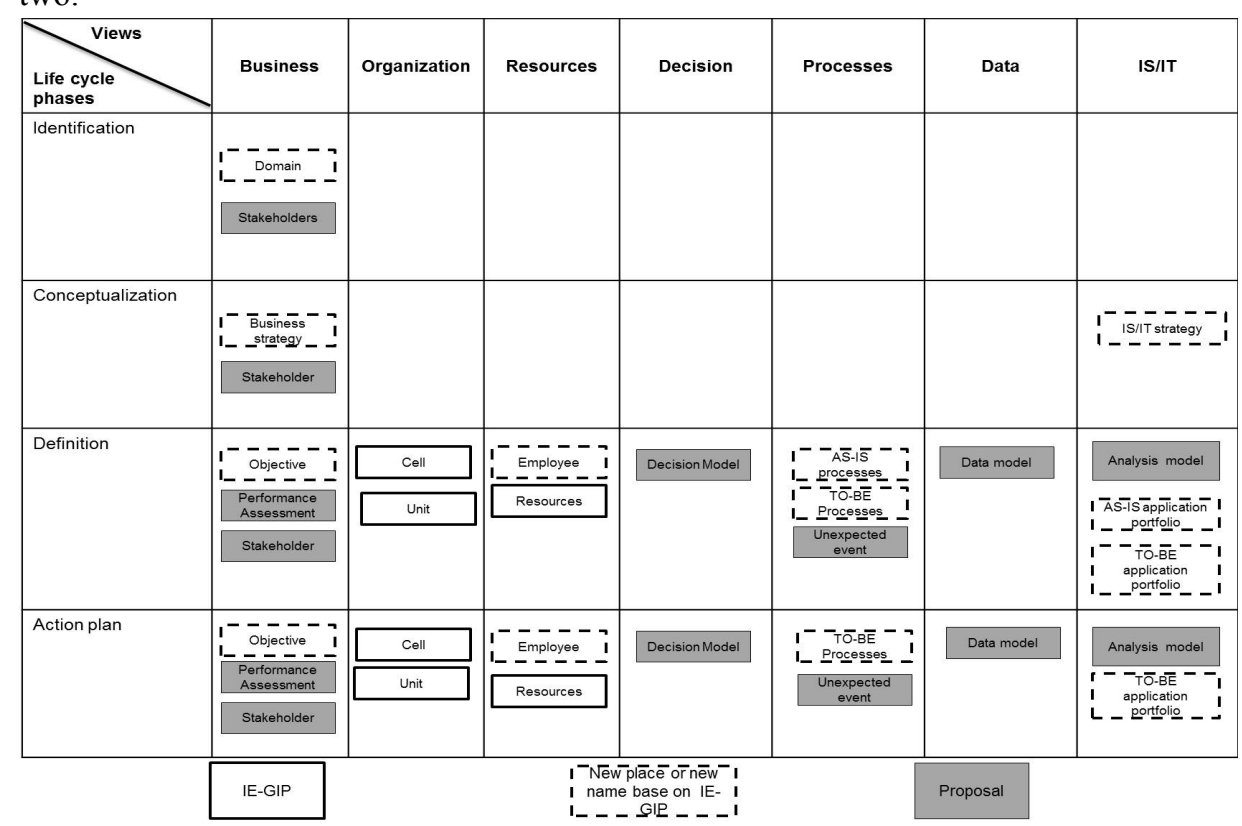

Figure 5. Situation building blocks proposed vs. IE-GIP

3. Business strategy (BS) represents the mission, vision, values, goals, strategy, plans, critical success factors, policies and parameters of the collaborative network that are agreed at a business level and have to be aligned with the IS/IT strategy.

4. IS/IT strategy (IS) represents the mission, vision, goals, plans, critical success factors, policies and parameters of the collaborative network that are agreed at the technological level and have to be aligned with the business strategy.

5. Objectives $(\boldsymbol{O B})$ represent the goals of the collaborative network for modelling the domain. The objectives of the collaborative network have to be specified in quantitative terms, in order to evaluate if they are being fulfilled during the collaborative process.

6. Performance assessment (PI) helps to measure the performance of the collaborative network through KPI (key performance indicator) that are assigned to measure each of the objectives of the collaborative network. 
7. $\boldsymbol{A S}$-IS process $(\boldsymbol{A P})$ define at a macro-level the processes that are currently being developed in the domain of the collaborative network at a local level.

8. AS-IS App. Portfolio (PA) helps to identify the information associated with each current local application, and its importance to support the global operations of the collaborative network.

9. TO-BE process (CP), the purpose of this building block is to define the processes of the collaborative network in the global domain that can group different stakeholders' processes.

10. Organizational cell (OC) represents the team participation in the collaborative network. Those cells form the organizational structure of the collaborative network, taking into account the know-how that each stakeholder can provide.

11. Organizational unit $(\boldsymbol{O U})$ represents the members of the collaborative network and their roles. Each unit must belong to at least one cell and each cell must have at least one member.

12. Employee $(\boldsymbol{E P})$ represents a member from each stakeholder that participates in the collaborative process. The difference between employee and organizational unit is related to the collaborative network and employee is related to stakeholder. However, organizational units and employees are related to one another.

13. Resources (RE) represent all those physical resources necessary to carry out the operation of the collaborative network.

14. Unexpected events (UE), the purpose of this building block is to support the decision process when unexpected events occur that affect production planning. There are four different origins of an event: customer, supplier, production and resource.

15. Decision modelling (DM), through this building block the decision models of the collaborative network are defined, taking into account the organizational hierarchy of the collaborative network.

16. Analysis model (AM) defines the operation and interaction of decision modelling and data modelling.

17. Data modelling $(\boldsymbol{D} \boldsymbol{A})$ defines the data structure related to the decision modelling and its relationship with the analysis model and TO-BE App portfolio.

18. TO-BE App. Portfolio (PC) represents the list of applications or services with which the collaborative network supports joint business processes.

For each cycle phase and its related building blocks an Entity Relationship diagram (E-R diagram) has been create, in order to fully understand the integration and interconnection between the proposed building blocks. Figure 6 is an example of this E-R for life cycle phase "action plan". This E-R diagram has been adapted to distinguish the different entities or building blocks and their main attributes, belonging to different views, so we have used different keys for each view, in order to facilitate the reading of the diagram. 


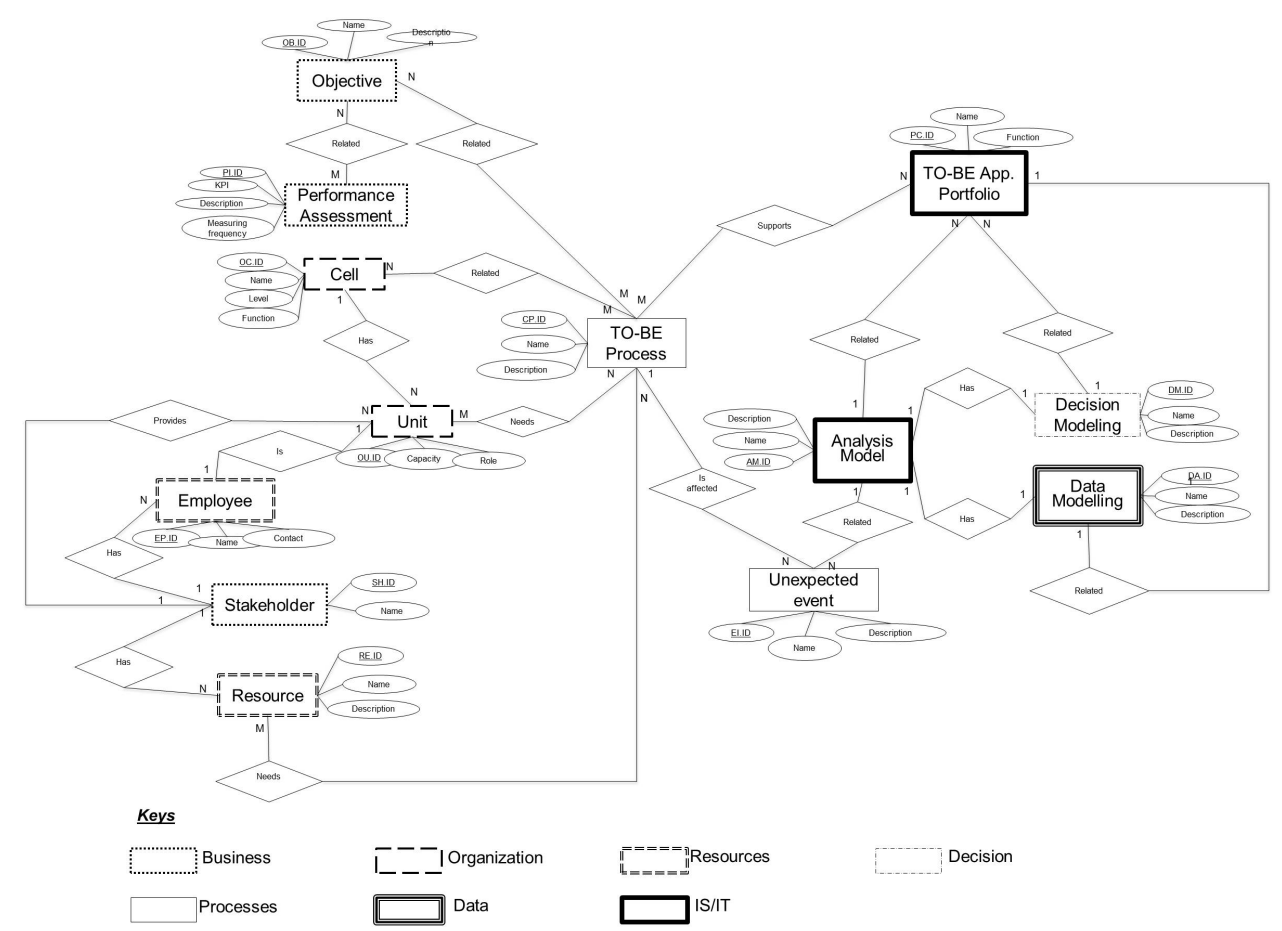

Figure 6. E-R diagram for life cycle phase "action plan"

The proposed building blocks are based on previous work, which also used modelling languages for building blocks $[\mathbf{1 1 , 5 5 ]}$. The building blocks defined in this proposal have two components: textual description and template. Some IE-GIP building blocks have been preserved in the proposed conceptual model; however the templates have been modified to include elements necessary to cover the problem of handling unexpected events. The textual description defines the building block and the intended use. The template defines and organizes the attributes building blocks in a formal way using a common pro forma. The template used for each building block maintains the following structure:

- Header: the header background is demarcated in a different color in order to separate the header from the body. The header contains the attributes related to the identification of the building blocks and its modelling context includes the following elements: building block label, identifier, name and unit responsible for design.

- Body: the body contains the particular attributes that are specific to each building block. The body is divided into two parts: descriptions that contain the descriptive attributes of the building block, which include those that are predefined in the template that can be added by the user to meet specific needs. Relationship of attributes may include, for example: operational relationships, specialization relationships, and partnerships. 
An example of the template designed for modelling the building block "Unexpected event" is shown in Table 2. This template is used in the life cycle phase "definition" to determine historical events that have affected production planning and the solutions provided for the specific events.

Table 2. Template building block "Unexpected event"

\begin{tabular}{|c|c|}
\hline \multicolumn{2}{|c|}{$\begin{array}{l}\text { Label: UE } \\
\text { Identifier: UE-<\#> } \\
\text { Unit responsible for design: <Unit> }\end{array}$} \\
\hline \multicolumn{2}{|c|}{ Process related: $<$ ID TO-Be process $>$} \\
\hline Kind of event ( Originated by) & Select from a list: Resource, Customer, Supplier, Production \\
\hline Name of the event & $\begin{array}{l}\text { Depends on the previous selection. Select from a general } \\
\text { sub list, which will depend on the specific collaborative } \\
\text { network. An example of this sus list is shown in Table } 1 \text {. } \\
\text { However, if the event cannot be described for the sub list, it } \\
\text { is possible to add a new one. }\end{array}$ \\
\hline Description & $<$ Text> \\
\hline Date of the event & $<$ Date $>$ \\
\hline Duration & $\begin{array}{l}\text { Select from a list: From } 1 \text { to } 24 \text { hours, From } 1 \text { day to } 3 \text { days, } \\
\text { from } 4 \text { days to } 7 \text { days, more than } 7 \text { days }\end{array}$ \\
\hline Criticality & Select from a list: High, medium, low \\
\hline Affected: & $\begin{array}{l}\text { Select from a list: Strategic plan, Tactical plan, Operational } \\
\text { plan }\end{array}$ \\
\hline Solution of the event & $<$ Text $>$ \\
\hline Kind of solution ( Solved by) & Select from a list: Resource, Customer, Supplier, Production \\
\hline ID solution & $\begin{array}{l}\text { Depends on the previous selection, select the ID of the } \\
\text { element that solved the event. }\end{array}$ \\
\hline Satisfaction level qualification & Select from a list: $1,2,3,4,5$ \\
\hline
\end{tabular}

In Section 2.2 four different entities of unexpected events were defined. The specific list of events for each entity will depend on each collaborative network. The classification in Table 1 provides to have a wider understanding of specific events that can affect operations in production planning. After categorizing the specific event and its ID, it is necessary to capture information about a specific description of the event, duration, criticality, type of planning affected, what solution was provided to solve the issue, and which element was involved in the solution, as well as the level of satisfaction for that solution. 


\subsection{Methodology}

The methodology guides in implementing the framework step by step using the building blocks for modeling and supporting decision-making in situations of unexpected events affecting the collaborative hierarchical production planning. The methodology should represent the phases of the life cycle of the framework of a detailed level [11]. The methodology is made up of 26 steps and is outlined in Figure 7. It shows the relationships between the building blocks, which are underlined. The information needed for each building block needs to be collected systematically, as shown in the diagram.

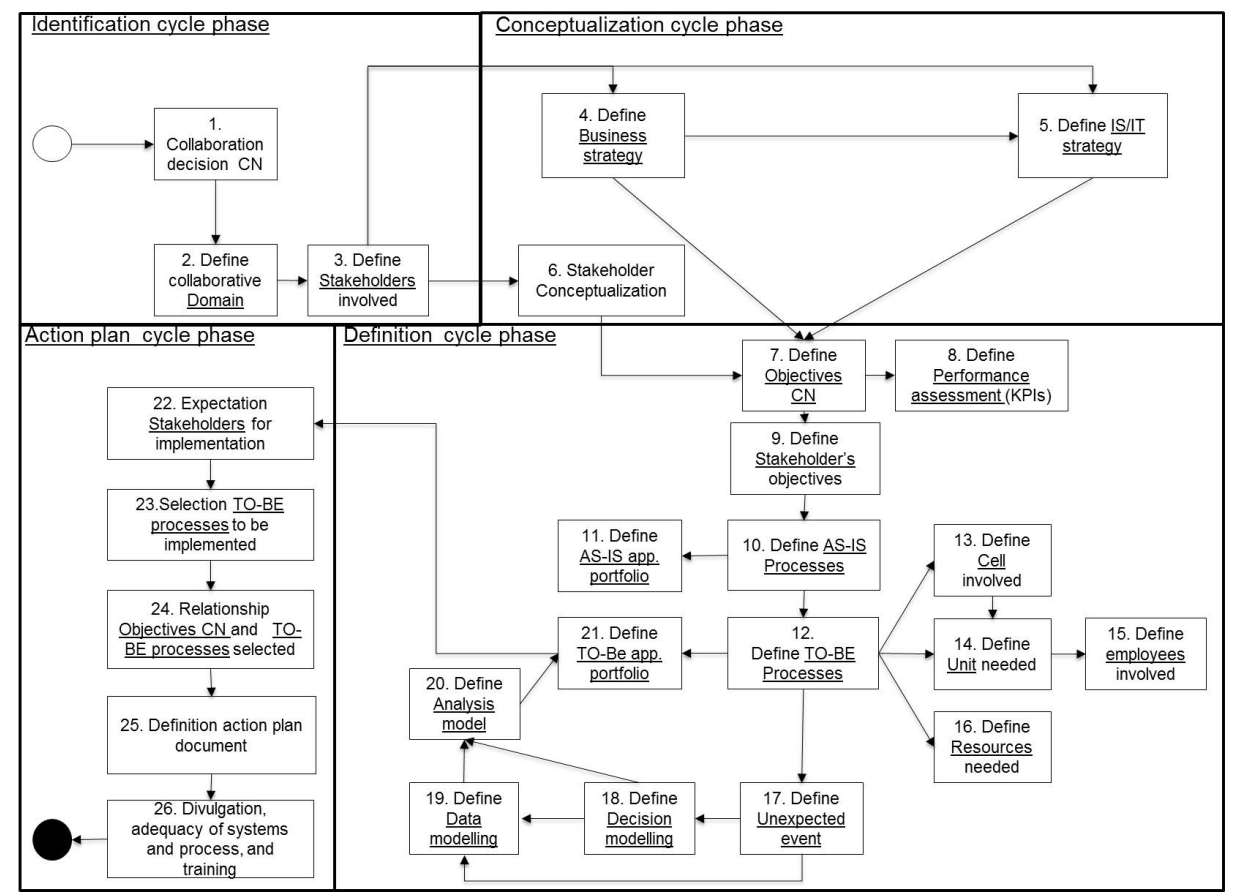

Figure 7. Methodology and relationship with framework's life cycle phases

Once, the collaborative network decides to collaborate in the domain of hierarchical production planning and specifically to solve the problem of unexpected events handling, it is necessary to define the partners ("Stakeholders") involved in the collaboration. The stakeholders define the "Business strategy" and "IS/IT strategy", which have to be aligned with each other. Based on these strategies the "objectives" for the collaboration are defined. Based on the set objectives established the "performance assessment" is defined. The "AS-IS process" of each organization is described, with the "AS-IS applications portfolio" that supports operations. The "TO-BE processes" are proposed in order to integrate the current process and make them smoother and more efficient as well identifying the "TO-BE applications portfolio" needed to support the operations. Each stakeholder contributes human resources ("Employee"). Each employee has roles and 
responsibilities within their organization. However in the context of collaboration each employee becomes an organizational "unit" that has his/her own roles and responsibilities and those may be different to what she/he does in his/her organization. These units make up organizational "cells" in order to become an integral and holistic team. Each stakeholder also contributes physical "resources" in order to achieve the established objectives. Taking into account the process, the "unexpected events" are defined. "Decision modelling" is defined based on the TO-BE process and unexpected events definition. "Data modelling" represents the data requirements of decision modelling. "Analysis modelling" needs the information provided by the decision modelling and the data modelling to be processed through the defined TO BE application portfolio. Finally the collaborative network needs to select processes to be implemented, its relationship with the objectives defined, document the action plan and prepare process, systems and training for the implementation once the collaborative network approves the plan.

\section{Case study and findings}

The proposed conceptual model has been applied to two companies in a Spanish collaborative network (shaded in black) from the ceramic tile sector (CN-TS). Figure 8 shows the supply chain structure of the CN-TS and where the proposed conceptual model was applied (shaded black). The companies shaded in grey represent sister organizations from the collaborative network.

Our proposal can be extended to the whole CN-TS and its different companies. However, for illustration and validation the proposed conceptual model has only been applied to two companies (leader and supplier) due to complexity and limitation of space. This validation proves the effectiveness of the proposed conceptual model for modelling unexpected events in the context of hierarchical production planning using interenterprise architecture to facilitate decision making. In order to achieve this goal, the methodology will provide a step by step guide for the collaborative network to understand the implementation of the proposed conceptual model and how to use the building blocks. To maintain confidentiality and anonymity, the building block labels have been used to describe each step in the building block: 


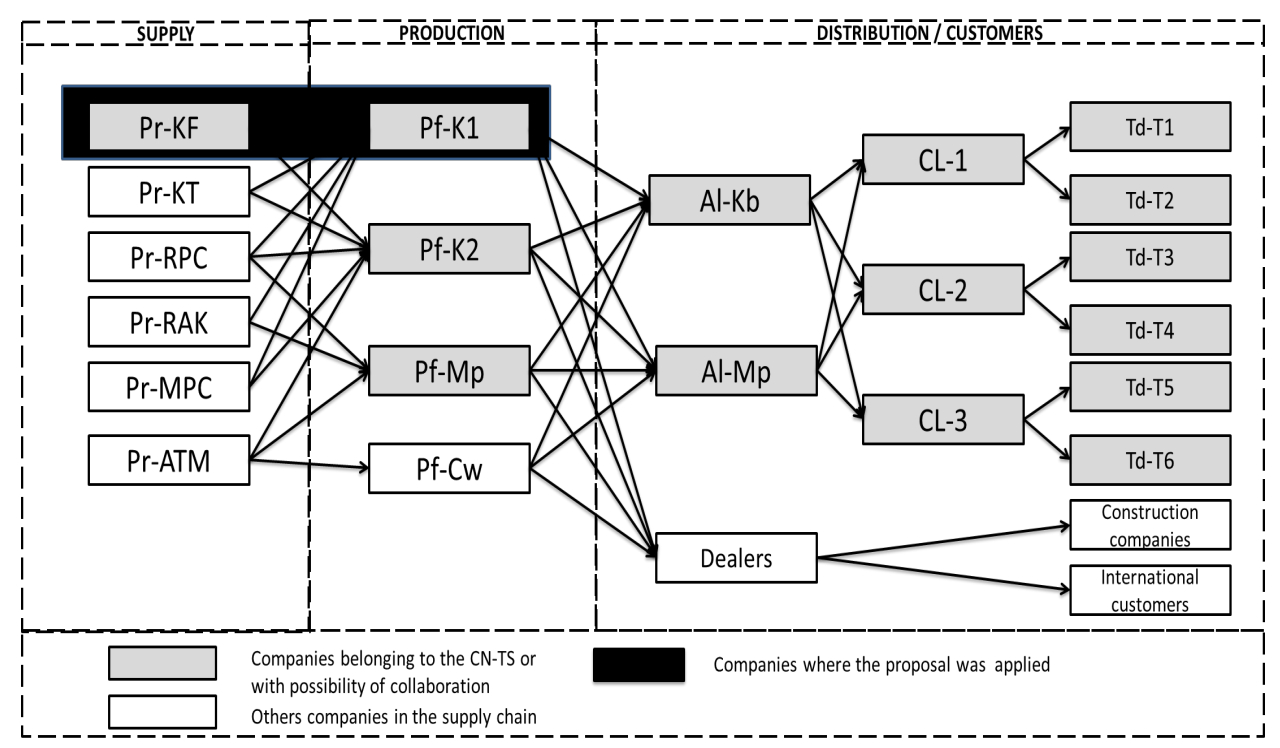

Figure 8. Supply chain structure of CN-TS

Identification life cycle phase

1. This group of companies has previously collaborated in production planning and has successfully implemented a hierarchical production planning system. However, the unexpected events issue has not been addressed and each decision maker makes a decision when an unexpected event occurs, based on her/his expertise and knowledge to ensure business continuity. Therefore, some companies in this collaborative network decided to collaborate in order to address this specific problem.

2. The collaborative domain DO-1 definition is: Collaborative production planning and unexpected events handling. The information collected in this building block provides an understanding of the reasons behind the decision for joint the collaboration process. A set of questions is formulated to define the impact of this collaboration for business continuity.

3. The stakeholders involved in this domain are: SH-1 and SH-2, the leader and its main supplier, respectively. Information, such as, strategy, employees involved, description of activities, previous collaboration agreements, and results of the collaboration are collected.

Conceptualization life cycle phase

4. Stakeholders define the business strategy (BS-1), which captures information about the conceptual definition of, for example, vision, mission, and values. The general ideas about solving the problem of unexpected events are captured in this template. It is also important to define how this strategy is related and aligned to the IT strategy.

5. Stakeholders define the IS/IT strategy (IS-1), which captures information about the conceptual definition of the technology strategy, the aims and objectives. The main 
ideas about how IT can help to solve the problem about unexpected events management are captured in this template. It also defines questions about alignment between both strategies and space to consider improvements.

6. Stakeholder conceptualization, questions about conceptualization for each stakeholder is answered through the extension of templates SH-1 and SH-2.

Conceptualization life cycle phase

7. Based on the business and IS/IT strategies in the context of the collaborative domain the defined objectives are: OB-1 (Improve unexpected events handling process), OB-2 (Reduce supply chain costs), OB-3 (Improve customer service and responsiveness), OB-4 (Improve collaboration between companies) and OB-5 (Improve accomplishment of production plans).

8. Based on the set objectives, the performance assessment is defined. The defined key performance indicators are: PI-1 (Customer satisfaction), PI-2 (Number of customer complaints), PI-3 (Total costs), PI-4 (Level of buyer-supplier collaboration), PI-5 (Responsiveness to unexpected events) and PI-5 (Efficiency of master production plan). The frequency of measurement of indicators is also stablished.

9. Stakeholders objectives, based on the objectives established for the $\mathrm{CN}$ each stakeholder defines its own objectives through the extension of templates SH-1 and SH-2.

10. The companies have already started a collaborative process in the hierarchical production planning process, therefore it is not necessary to collect information about AS-IS process, because they are already operating in the $\mathrm{CN}$ processes for this specific domain.

11. In addition to the previous step, the companies are already using the application portfolio to fulfill the need of the $\mathrm{CN}$ process and therefore for this case study, it is not necessary to accomplish this step.

12. The defined TO-BE processes are: CP-1 (Strategic Production Planning), CP-2 (Tactical Production Planning), CP-3 (Operative Production Planning) and CP-4 (Unexpected events handling). Each process has its own inputs, outputs, restrictions and dependencies.

13. The organizational cells are defined taking into account that each cell has to synergistically accomplish common objectives. Each cell has its own responsibilities and is made up of the organizational units defined in the followings step. OC-1 (Planning cell).

14. Organizational units are defined based on the necessities of each CP Process. OU-1 (Performance assessment manager), OU-2 (Planning manager), OU-3 (Purchasing planner), OU-4 (Commercial assistant), OU-5 (Production planner plant-1), OU-6 (Production planner plant-2), OU-7 (General planning manager), OU-8 (Operative panning manager) and OU-9 (IT/IS manager). For each unit the roles and capacities are assigned.

15. Employee details, such as contact and roles within the organization for each stakeholder is collected (EP-1 to EP-9). It may or may not be the same roles they 
have in his/her own organization, but it would depend on the needs to fulfill the goals in the collaboration, using his/her skills and knowledge to accomplish the common objectives.

16. Each company maintains its own resources in order to continue with the daily processes. It is important to identify where the data is going to be gathered from and where the results of the modeling are going to be shared. Therefore the resources needed are: RE-1 (Database), RE-2 (Online repository), RE-3 (Materials), RE-4 (Components) and RE-5(Final products).

17. It is necessary to extend this step because it is the focus of the current research. Information collected through surveys with different managers from the CN-TS, allowed us to identify different kinds of events, not previously included. The extension is reported in Table 1. The template filled in this step is the UE-1. The current unexpected events handling in the CN-TS is treated quite differently according to the event source, the source can be: customer, supplier, production or resources. Below is a description of how CN-TS handles each kind of event and which organizational units are involved in the solution of the event:

- $\quad$ Event caused by a customer: If a customer returns a product or cancels an order or changes an order, the person directly responsible for resolving the event is the Commercial Manager. Each of the events that fall within this category should be treated differently, for example if there is a refund for quality problems in the product, it is necessary to open a nonconformity that is systematically documented until the solution is provided. All members of the organization who are involved in the resolution of the incident, should document the actions that provide solutions into the system.

- $\quad$ Event caused by a supplier: The events originate from a supplier and can be categorized into two different types: failure to deliver or nonconformities in the material supplied. If a supplier cannot meet a deadline, the supplier reports the event to the purchasing manager, who then decides how to handle the incident depending on their relevance in terms of duration of the impact and how this affects planning and missing production. On the other hand, if the supplied materials exhibit nonconformity recorded at the time of receipt of the goods by quality area, nonconformity is communicated to purchasing area that is responsible for conducting the respective management with the supplier in order to reprocess materials, material replenishment, or order cancelation to the supplier and/or generate a new order.

- $\quad$ Event generated in production: in this category quality problems or variations are included in the processing times of the production line. The quality control process is quite rigorous in the $\mathrm{CN}-\mathrm{TS}$; the products depending on the process are classified into three different qualities and sold to different types of customers depending on product quality. However, due to the high quality standards that are still in the production process, it is very difficult to have too many low quality products. According to recent statistics the high quality product is approximately $97 \%$ of current production. There is no evidence of past records of events in this category. However, it is recommended to start collecting this information into the events template. 
- $\quad$ Event generated by resources: The resources taken into account in defining the architecture are physical resources, such as machines and tools and human resources. A maintenance plan for machines and tools is tightly controlled to ensure that unexpected events are managed. On the other hand, currently there are no risks for labor problems, due to the economic situation in the country; workers are very committed and the possibility of a strike by workers or working below their expected performance is almost zero. Even given these conditions, it is recommended to keep track of this kind of events.

All event data is currently being managed in different areas, and the analysis of that information is still ongoing.

18. The decision model for hierarchical production planning has been applied to the case study. Alemany [3] gives a detailed description of the application of this system in CN-TS. As our focus is on handling unexpected events, the decision model DM-1 (Decision model to handle unexpected events) for this problem uses case based reasoning.

19. The data modeling DA-1 (Data modelling to handle unexpected events) is linked with the decision model. This data provides the required information for the decision maker to identify alternative solutions for the different kinds of unexpected events, based on past experiences and historical data to gain a better understanding of the whole situation.

20. The analysis model AM-1 (Analysis modelling to handle unexpected events) focusses on how decisions makers are able to get to the information provided by the decision modelling and data modelling supported, by the TO-BE applications portfolio.

21. The CN-TS supports merging all the systems into a unique ERP. It is necessary to have decision support systems to handle unexpected events centrally. The $\mathrm{CN}$ applications portfolio is: PC-1 (ERP-SAP) and PC-2 (DSS-Handling events).

Action Plan life cycle phase

22. Expectation stakeholder for implementation, the extension of templates SH-1 and SH-2 related to expectation of each stakeholder for implementation is completed in this step.

23. Processes to be implemented are selected and the extension of templates in this life cycle phases are completed: CP-1 (Strategic Production Planning), CP-2 (Tactical Production Planning), CP-3 (Operative Production Planning) and CP-4 (Unexpected events handling).

24. The relationship between objectives $\mathrm{CN}$ and TO-BE process are reported thought the extension of templates: OB-1 (Improve unexpected events handling process), OB-2 (Reduce supply chain costs), OB-3 (Improve customer service and responsiveness), OB-4 (Improve collaboration between companies) and OB-5 (Improve accomplishment of production plans).

25. Although this document does not have an associated template. All templates documented in the methodology are part of the document. This document allows the $\mathrm{CN}$ understands how the plan will be implemented through the implementation of 
the TO-BE processes and the relationship and integration of all elements of the proposed inter-enterprise architecture.

26. Finally, our intention is to communicate the modelling to everyone involved in the process of evaluating the implementation. However, it is also necessary to prepare the training materials and communications about the use of the proposed conceptual model and how to get the best outcomes for the CN-TS.

In order to show how the documentation of the IEA looks like, Table 3 shows the instantiation of building block "Stakeholder". This template has extensions in each one of the life cycle phases.

Table 3. Instantiation template building block "Stakeholder-1"

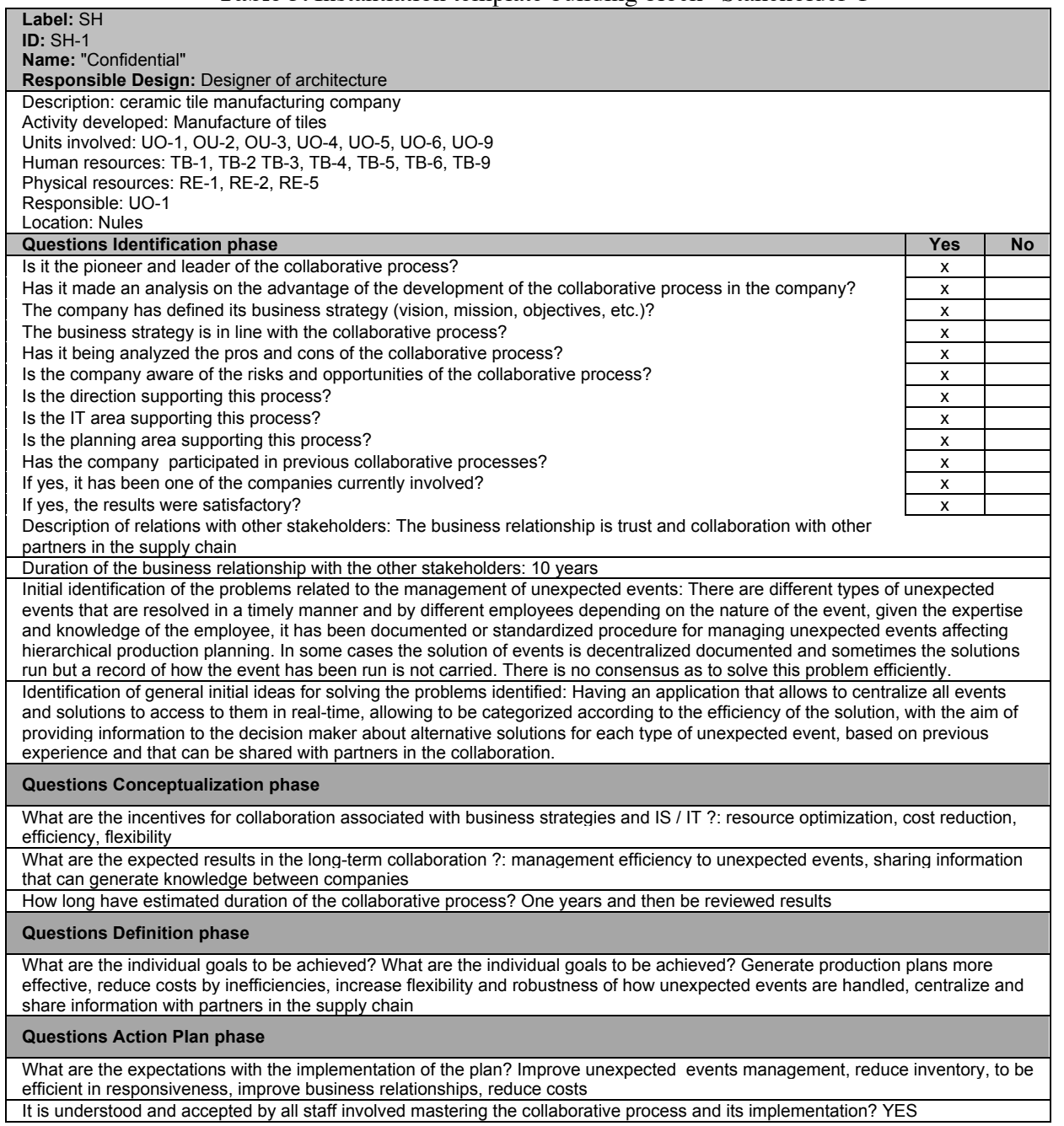


The initial findings of this case study are promising. The proposed methodology has helped to validate the use of the proposed conceptual model through the use of the building blocks and their respective templates, in the CN-TS. The methodology has been adapted to the conditions of the specific industry based case study. From the initial study the participants in the collaboration domain agree that these tools support better and timelier decision making for unexpected events. The data collected from the range unexpected events will enable the development of a consolidated data repository needed for real time decision making, by using historical information and the degree of success or quality of past decisions. However, it is also necessary to analyze scenarios where there is no information about past events and therefore no historical data to support the decision maker and this will be one of our future research lines.

\section{Conclusions}

This paper reports the need for an inter-enterprise architecture that allows decision makers to model the problem of unexpected events handling in hierarchical production planning that can be used by collaborative networks to support better and more efficient decisions. The proposed conceptual model includes: a partial framework that is an extension of the general framework IE-GIP to resolve specific problems of unexpected events handling in the context of hierarchical production planning. The modelling language is based on the definition of the building blocks that contain all the information about the different elements in the specific domain, and how the building blocks are inter-related. Finally the methodology identifies the steps for navigating through the framework with the integrated building blocks to model unexpected events handling in hierarchical production planning.

The proposed conceptual model was applied to a collaborative network in the Spanish ceramic tile sector. All unexpected events data is currently being managed in different non-centralised areas. Therefore, further analysis of that information is still ongoing. However, even at this early stage, the application of the proposed conceptual model demonstrates its flexibility to adapt to partial information and its potential for modelling and addressing the problem holistically. Further work will include complete analysis of the information on unexpected events; enhancement of the conceptual model; operationalising the model; and fully document and prepare communications and analyse how could be managed scenarios where there is no information about past events and therefore no historical data to support the decision maker.

\section{Acknowledgments}

This paper has been developed as a result of a mobility stay funded by the Erasmus + Mundus in framework of Traineeship Program. This research has been carried out in the 
framework of the project ADENPRO-PJP (Ref. PAID-06-21) funded by the Universitat Politècnica de València

\section{References}

[1] A. Vargas, A. Boza, L. Cuenca and I. Sacala, Inter-Enterprise Architecture and Internet of the Future, Technological Innovation for the Internet of Things, 394 (2013) 25-32.

[2] L. Cuenca, A. Boza and A. Ortiz, Architecting Business and IS/IT strategic alignment for extended enterprises, Studies in Informatics and Control, 20 (1) (2011) 7-18.

[3] M. Alemany, Metodología y Modelos para el Diseño y Operación de los Sistemas de Planificación Jerárquica de la Producción. Aplicación a una Empresa del Sector Cerámico, (PhD Thesis) Universidad Politécnica de Valencia, 2003.

[4] A. Vargas, A. Boza and L. Cuenca, Towards Interoperability Through Inter-Enterprise Collaboration Architectures, OTM 2011 Workshops, Vol. 7046 of LNCS, Springer, 2011, pp. 102-111.

[5] K. Kosanke, CIMOSA Primer on key concepts, purpose and business value, 1996

[6] D. Chen, B. Vallespir and G. Doumeingts, GRAI integrated methodology and its mapping onto generic enterprise reference architecture and methodology, Computers in Industry, 33 (1997) 387-394.

[7] T. Williams and H. Li, PERA and GERAM enterprise reference architectures in enterprise integration, Information Infrastructure Systems for Manufacturing , (1998) 3-30,

[8] FORCE, IFIP-IFAC Task, GERAM: Generalised Enterprise Reference Architecture and Methodology, IFIP-IFAC Task Force on Architectures for Enterprise Integration March Version, 1(3), 1998.

[9] A. Ortiz, Propuesta para el Desarrollo de Programas de Integración Empresarial en Empresas Industriales. Aplicación a una Empresa del Sector Cerámico, (PhD Thesis) Universidad Politécnica de Valencia, 1998.

[10] A. Ortiz, F. Lario and L. Ros, Enterprise Integration-Business Processes Integrated Management: a proposal for a methodology to develop Enterprise Integration Programs, Computers in Industry, 40 (1999) 155171.

[11] L. Cuenca, Marco arquitectónico para la propuesta IE-GIP. Extensión de la arquitectura CIMOSA. Aplicación a una empresa del sector cerámico, (PhD Thesis) Universidad Politécnica de Valencia, 2009.

[12] L. Cuenca, A. Boza and A. Ortiz, An enterprise engineering approach for the alignment of business and information technology strategy, Int. J. Computer Integrated Manufacturing, 24 (11) (2011), 974-992.

[13] L. Cuenca, A. Ortiz y A. Boza, Architecting Business and IS/IT Strategic Aligment for Extend Enterprises, Studies in informatics and control, 20(1) (2011b), 7-18.

[14] A. Scheer and K. Schneider, ARIS - Architecture of Integrated Information, Handbook on architectures of information systems, 3 (2006), 605-623.

[15] The Open Group, TOGAF® Version 9.1, 2011.

[16] A. Vargas, A. Boza, A. Cuenca and A. Ortiz, Towards a Framework for Inter-Enterprise Architecture to Boost Collaborative Networks, On the Move to Meaningful Internet Systems: OTM 2013 Workshops. vol. 8186 of LNCS, Springer, 2013, pp. 179-188.

[17] S. Bernard, An introduction to enterprise architecture, AuthorHouse, 2012.

[18] J. Mula, R. Poler, J. García and F. Lario, Models for production planning under uncertainty: A review, International Journal of Production Economics, 103 (1) (2006) 271-285.

[19] A. Boza, Propuesta de un Sistema de Información de Ayuda para la Toma de Decisiones en Planificación Jerárquica de la Producción, (PhD Thesis) Universidad Politécnica de Valencia,. 
[20] A. Boza, A. Ortiz, E. Vicens and R. Poler, A Framework for a Decision Support System in a Hierarchical Extended Enterprise Decision Context, Enterprise Interoperability. Lecture Notes in Business Information Processing,. 38, 2009, pp. 113-124.

[21] E. Vicens, M. Alemany, C. Andrés and J. Guarch, A design and application methodology for hierarchical production planning decision support systems in an enterprise integration context, International Journal of Production Economics, 74 (1) (2001) 5-20.

[22] J. Acevedo and G. Mejia, Programación Reactiva y Robusta de la Producción en un Ambiente Sistema de Manufactura Flexible: Llegada de Nuevas Órdenes y Cambios en la Prioridad de las Órdenes de Trabajo, 2006.

[23] E. Alvarez, Multi-plant production scheduling in SMEs, Robotics and Computer-Integrated Manufacturing, 23 (2007) 608-613.

[24] W. Van Wezel, D. Van Donk and G. Gaalman, The planning flexibility bottleneck in food processing industries, Journal of Operations Management , 24 (2006) 287-300.

[25] M. Palacios and M. Álvarez, Una herramienta de planificación de la producción para agilizar la gestión de la cadena de valor, Primer Congreso de Logística y Gestión de la Cadena de Suministro, Zaragoza, España, 2007.

[26] S. Darmoul, H. Pierreval and S. Hajri-Gabouj, Handling disruptions in manufacturing systems: An immune perspective, Engineering Applications of Artificial Intelligence, 26 (2013) 110-121.

[27] L. Bearzotti, E. Salomone and O. Chiotti, An autonomous multi-agent approach to supply chain event management, International Journal of Production Economics, 135 (1) (2012), 468-478.

[28] J. Váncza, L. Monostori, D. Lutters, S. Kumara, M. Tseng, P. Valckenaersf and H. Van Brussel, Cooperative and responsive manufacturing enterprises, CIRP Annals - Manufacturing Technology, 60 (2) (2011), p. 797-820.

[29] L. Monostori, E. Szelke and B. Kádár, Management of changes and disturbances in manufacturing systems, Annual Reviews in Control, 22 (1998) 85-97.

[30] B. Grabot, J. Blanc and C. Binda, A decision support system for production activity control," Decision Support Systems, 16 (1996) 87-101.

[31] X. Xu and G. Roland, Beyond Automation and Control: Manufacturing Information Systems from a Strategic Perspective, International Journal of Information Management, 17 (6) 437-449.

[32] M. Fox, M. Barbuceanu and R. Teigen, Agent-Oriented Supply-Chain Management, InformationBased Manufacturing, (2001) 81-104.

[33] E. Álvarez and F. Zubillaga, Análisis Comparativo de Métodos de Secuenciación para la Programación Dinámica de Operaciones, VIII Congreso de Ingeniería de Organización , Leganes, España, 2004.

[34] B. Kádár, A. Pfeiffer and L. Monostori, Discrete event simulation for supporting production planning and scheduling decisions in digital factories, Proceedings of the 37th CIRP International Seminar on Manufacturing Systems, Budapest, Hungary, 2004.

[35] M. Palacios, E. Álvarez, M. Álvarez and J. Santamaría, Lessons learned for building agile and flexible scheduling tool for turbulent environments in the extended enterprise, Robotics and ComputerIntegrated Manufacturing, 22 (5) (2006) 485-492.

[36] W. Shen, Q. Hao, H. Yoon and D. Norrie, Applications of agent-based systems in intelligent manufacturing: An updated review, Advanced Engineering Informatics, 20 (4) (2006) 415-431.

[37] K. Katragini, E. Vallada and R. Ruiz, Resecuenciación en talleres de flujo considerando múltiples eventos, XIII Congreso de Ingeniería de Organización, Barcelona, España, 2009.

[38] L. Monostori, G. Erdos, B. Kádár, T. Kis, A. Kovács, A. Pfeiffer and J. Váncza, Digital enterprise solution for integrated production planning and control, Computers in Industry, 61 (2) (2010) 112-126.

[39] W. Zhang and C. Van Luttervelt, Toward a resilient manufacturing system, CIRP Annals Manufacturing Technology, 60 (1) (2011) 469-472. 
[40] J. Shim, M. Warkentin, J. Courtney, D. Power, R. Sharda and C. Carlsson, Past, present, and future of decision support technology, Decision Support Systems, 33 (2002) 111-126.

[41] B. Dengiz, T. Bektas and A. E. Ultanir, Simulation optimization based DSS application: A diamond tool production line in industry, Simulation Modelling Practice and Theory, 14 (2006) 296-312.

[42] E. Turban, J. Aronson and T. Liang, Decision Support Systems and Intelligent Systems, Prentice, 2005 .

[43] D. Power and R. Sharda, Decision Support Systems, Handbook of automation, 87 (2009) 1539-1548.

[44] J. Al-Kassab, Z. Ouertani, G. Schiuma and A. Neely, Information visualization to support management decisions, International Journal of Information Technology \& Decision Making , 13(2) (2014). 407-428.

[45] W. van der Aalst, M. Weske and D. Grünbauer, Case handling: a new paradigm for business process support, Data \& Knowledge Engineering, 53 (2) (2005) 129-162.

[46] A. Hax and H. Meal, Hierarchical Integration of Production Planning and Scheduling, 1973.

[47] L. Weinstein and C. Chung, Integrating maintenance and production decision in a hierarchical production planning environment," Computers \& Operation Research, 26 (10) (1999) 1059-1074.

[48] H. Yan, X. Zhang and X. Ma, Karmarkar's and interaction/prediction algorithms for hierarchical production planning for the highest business benefit, Computers in Industry, 49 (2) (2002) 141-155.

[49] S. Hurtubise, C. Olivier and A. Gharbi, Planning tools for managing the supply chain, Computers \& Industrial Engineering, 46 (4) (2004) 763-779.

[50] A. Vargas, A. Boza, L. Cuenca, I. Sacala, and M. Moisescu, Towards the Development of the Framework For Inter Sensing Enterprise Architecture, Journal of Intelligent Manufacturing, (2014).

[51] J. Vesterager, M. Tølle and P. Bernus, VERA: Virtual Enterprise Reference., GMNBook, GLOBEMEN final plenary, 2002.

[52] O. Adam, A. Hofer, S. Zang, C. Hammer, M. Jerrentrup and S. Leinenbach, A Collaboration Framework for Cross-enterprise Business Process Management, in First International Conference on Interoperability of Enterprise Software and Application, Geneva, 2005.

[53] J. Schekkerman, Extended Enterprise Architecture Framework Essentials Guide,” 2006.

[54] A. Boza, A. Ortiz and L. Cuenca, A Framework for Developing a Web-Based Optimization Decision Support System for Intra/Inter-organizational Decision-Making Processes, Balanced Automation Systems for Future Manufacturing Networks, 322 (2010) 121-128.

[55] ISO/CEN 19440, Enterprise integration - Constructs for enterprise modelling, 2008. 